RUNNING HEAD: CONTEXTUAL ACCEPTANCE OF INSECTS

\title{
Contextual acceptance of insect-based foods
}

Forthcoming in Food Quality and Preference

\section{Names and affiliations:}

Kosuke Motoki ${ }^{1,2}$, Shin-ichi Ishikawa ${ }^{1}$, Charles Spence ${ }^{3}, \&$ Carlos Velasco ${ }^{4}$

${ }^{1}$ Department of Food Management, School of Food, Agricultural and Environmental Sciences, Miyagi University, Sendai, Japan;

${ }^{2}$ Institute of Development, Aging and Cancer, Tohoku University, Sendai, Japan;

${ }^{3}$ Department of Experimental Psychology, University of Oxford, Oxford, UK;

${ }^{4}$ Centre for Multisensory Marketing, Department of Marketing, BI Norwegian Business

School, Oslo, Norway.

Correspondence to: Kosuke Motoki, Department of Food Management, School of Food, Agricultural and Environmental Sciences, Miyagi University, 2-2-1 Hatatate, Taihaku, Sendai, 982-0215, Japan.

E-mail: motokik@myu.ac.jp 


\begin{abstract}
Insect-based foods have gained much attention as an alternative source of protein in recent years because of their high nutritional content and low production costs. However, consumer acceptance of insect-based foods still poses a big challenge in many societies. Across three studies, we examined how social companions (alone, friend, family, acquaintance, partner) and location (cafe, bar, pub, food festival) are associated with people's willingness to eat insect-based foods. We also examined the positive arousing (fun, excitement) and positive calming (romance, tranquility) emotions that were evoked by several eating contexts. The results of Studies 1 and 2 revealed that participants expected that they would be more willing to eat insect-based foods with friends (vs. alone, family, acquaintance, partner) and in pubs and at food festivals (vs. in a cafe, bar). The results of Study 3 replicated the main findings of the first two studies using the actual names (not pictures) of insect-based food products, namely 'mealworm burger' and 'cricket chocolate bar'. Moreover, these contexts, where people would be more willing to eat insect-based foods, were associated with positive arousing emotions (fun, excitement) rather than positive calming emotions (romance, tranquility). Taken together, then, these findings reveal the role of contexts associated with positive arousing emotions in eating insect-based foods and provide practical advice concerning the situations in which the consumer's acceptance of insect-based foods may be increased.
\end{abstract}

Keywords: Insect-based foods; Contexts; Positive Emotions; Social companions; Locations 


\section{HIGHLIGHTS}

- We studied the role of context in the acceptance of insect-based foods.

- Eating with friends enhanced the acceptance of insect-based foods.

- Eating in pubs and food festivals enhanced the acceptance of insect-based foods.

- Positive arousing emotions might increase the acceptance of insect-based foods. 


\section{INTRODUCTION}

With a growing population, producing sufficient protein from traditional food resources (e.g., livestock, poultry, and fish) is expected to become increasingly challenging in the future (Willet et al., 2019). One of the proposed solutions to solve this issue involves the use of insect matter in food. This solution is attractive inasmuch as many varieties of insects constitute a rich source of protein. What is more, production processes are more sustainable than those for traditional food resources (Deroy, Reade, \& Spence, 2015; Willet et al., 2019). Although there has been much interest in the potential benefits associated with eating insects, most consumers in economically developed countries remain reluctant to try them in any context other than as a novelty item (Hartmann \& Siegrist, 2017; Verbeke, 2015).

\section{Potential role of environmental situations in insect-based food acceptance}

A growing body of research highlights the fact that there are multiple determinants (e.g., demographic variables, personality, and methods of food preparation) influencing the acceptance of insect-based food (Hartmann \& Siegrist, 2017). However, further research is urgently needed in order to clarify how contextual factors influence the acceptance of insectbased foods. Situational factors are anything that occurs in the surroundings of the eater and are regarded as key factors influencing both food choice and consumer behaviour (Cardello \& Meiselman, 2018; Spence, 2017). They include social and physical surroundings.

\section{Social influences on the acceptance of insect-based food}

Previous research has examined social influences on the acceptance of insect-based food. For instance, Berger et al. (2019) demonstrated that social norms or conformity (i.e., other people's food evaluations) affect the likelihood of people accepting insect-based foods. It remains unclear, however, whether the mere presence of others influences the acceptance of insect-based food, even though they do not express any guiding opinions. Social situation includes group characteristics (e.g., friends, partner, family; e.g., Ruddock et al., 2019; Spence, 2017). Eating behaviours are likely to be influenced by the group (and related characteristics) with whom people eat considering that each group comes with a series of social norms, as well as positive emotions which may set the stage for eating (Higgs \& Thomas, 2016). This study therefore investigated how the presence of others with different characteristics (e.g., friends, partner, family) influences the acceptance of insect-based foods.

\section{Location (or context) influencing the acceptance of insect-based foods}


Earlier studies have demonstrated that the location can influence the acceptability of foods (Cardello \& Meiselman, 2018). In particular, the degree to which people accept a food has been shown to depend on the interaction between the type of food and the eating situation. Although the relevant literature has investigated the influence of eating location (larger supermarket, local/street market, and kiosk) on the acceptance of insect-based foods (Alemu et al., 2017), previous research used narrowly-defined location categories (i.e., within a local or larger supermarket). Consequently, it remains unknown whether widely different locations would influence the acceptance of insect-based foods differently. In the present research, we therefore investigated whether specific hypothetical locations (such as a bar or restaurant) would influence people's self-reported willingness to eat insect-based foods. Similar to what happens with social situation, one might expect that the appropriateness of a given eating location, and its associated emotions would increase (or not) the acceptance of specific foods.

\section{Emotions and food acceptance}

Incidental emotions derived from situations in which one eats have also been shown to influence subsequent food-related judgments and behaviours (e.g., Motoki \& Sugiura, 2018). Evoked emotions differ as a function of the context in which people imagine consuming, or actually do consume various food products (e.g., Piqueras-Fiszman \& Jaeger, 2014). Positive emotional terms are more often used when food products are consumed in appropriate situations (Piqueras-Fiszman \& Jaeger, 2014). Although earlier research has shown that food-evoked emotions influence the consumer acceptance of insect-based foods (e.g., Lammers et al., 2019), to date, we are not aware of any study having investigated how context-evoked emotions contribute to the acceptance of insect-based foods. Given that appropriate contexts evoke positive emotions, it might be inferred that the influence of social situation and locations on the acceptance of insects as a source of food is derived from positive emotions experienced under those situations.

We hypothesized that positive arousing emotions (in particular, fun and excitement) might explain, at least in part, the influence of social situation and locations in which people are more likely to eat insect-based foods. Core affect theory indicates that emotions vary along two dimensions: valence and arousal (Prescott, 2017, Russell, 2003). Recently, it has been shown that people with higher sensation-seeking are more likely to accept insect-based foods (e.g., Lammers et al., 2019). Those with higher sensation-seeking reportedly prefer novel and intense experiences (Zuckerman, 1990), which might be related to positively arousing (e.g., fun and exciting) situations rather than, say, to those situations that are rated as positively calming (e.g., romantic and tranquil). Previous research has measured the conceptual elements of sensation seeking based on fun and excitement (Stephenson et al., 2003). Thus, 
we assume that fun and excitement may be appropriate emotions in order to cover positive arousing emotions, though no previous research has directly examined whether fun and excitement are associated with insect-based foods.

\section{Present study}

With these ideas in mind, the present study was designed to investigate how situational factors are associated with the acceptance of insect-based foods. Studies 1 and 2 examined how social situation and eating location influence people's expected willingness to eat insectbased foods and the expected emotions evoked. Social situation includes alone, friend, family, acquaintance, and partner. Locations include cafes, bars, pubs, and food festivals. In Study 3, using the actual names of insect-based foods (mealworm burger, cricket chocolate bar), we strove to replicate and expand the results obtained in our first two studies. It can be expected that people would be more willing to eat insect-based foods with others (rather than when alone) or in food festivals/pub (rather than cafe/bar), given that these contexts might be associated with positive arousing emotions.

\section{METHODS}

In this section, we will present the methods for the three studies conducted, specifying what was common and what varied across them.

\section{Participants}

All the Japanese participants in all studies were recruited on Lancers (https://www.lancers.jp/) and completed a survey on Qualtrics (https://www.qualtrics.com/jp/). All of the studies described herein were approved by the ethics committee of Miyagi University and were conducted in accordance with the Declaration of Helsinki. Summaries of each study are presented in Table 1.

Table 1. Summary of the three studies conducted.

\begin{tabular}{|l|l|l|l|}
\hline & Study 1 & Study 2 & Study 3 \\
\hline n collected & 100 & 107 & 104 \\
\hline Final n & $\begin{array}{l}96(4 \text { excluded } \\
\text { because at least one }\end{array}$ & $\begin{array}{l}104(3 \text { excluded } \\
\text { because at least one }\end{array}$ & 104 \\
\hline
\end{tabular}




\begin{tabular}{|c|c|c|c|}
\hline & $\begin{array}{l}\text { question dataset was } \\
\text { missing) }\end{array}$ & $\begin{array}{l}\text { question dataset } \\
\text { was missing) }\end{array}$ & \\
\hline Gender & 31 females & 32 females & 51 females \\
\hline Age & $\begin{array}{l}M=41.1 \text { years, } S D= \\
9.3\end{array}$ & $\begin{array}{l}M=42.9 \text { years, } S D \\
=10.5\end{array}$ & $\begin{array}{l}M=39.9 \text { years, } S D= \\
9.4\end{array}$ \\
\hline $\begin{array}{l}\text { Proportion of those } \\
\text { who had eaten } \\
\text { insect-based foods } \\
\text { previously }\end{array}$ & $41 \%$ & $38 \%$ & $34 \%$ \\
\hline Contexts & $\begin{array}{l}\text { Social situation } \\
\text { (alone, friend, } \\
\text { family, } \\
\text { acquaintance, } \\
\text { partner) }\end{array}$ & $\begin{array}{l}\text { Locations (cafes, } \\
\text { bars, pubs, food } \\
\text { festivals) }\end{array}$ & $\begin{array}{l}\text { Social situation (alone, } \\
\text { friend, family, } \\
\text { acquaintance, partner) } \\
\text { Locations (cafes, bars, } \\
\text { pubs, food festivals) }\end{array}$ \\
\hline $\begin{array}{l}\text { Expected emotions } \\
\text { evoked by contexts }\end{array}$ & $\begin{array}{l}\text { Positive arousing } \\
\text { (fun, excitement) }\end{array}$ & $\begin{array}{l}\text { Positive arousing } \\
\text { (fun, excitement) }\end{array}$ & $\begin{array}{l}\text { Positive arousing (fun, } \\
\text { excitement) } \\
\text { Positive calming } \\
\text { (romance, tranquility) }\end{array}$ \\
\hline Food type & $\begin{array}{l}\text { Insect-based foods } \\
\text { (general category) } \\
\text { Typical foods } \\
\text { (general category) }\end{array}$ & $\begin{array}{l}\text { Insect-based foods } \\
\text { (general category) } \\
\text { Typical foods } \\
\text { (general category) }\end{array}$ & $\begin{array}{l}\text { Insect-based foods } \\
\text { (mealworm burger, } \\
\text { cricket chocolate bar) } \\
\text { Typical foods (beef } \\
\text { hamburger, chocolate } \\
\text { bar) }\end{array}$ \\
\hline
\end{tabular}

Note that the sample sizes were based on recent studies examining sensory and consumer science using online experiments (e.g., Motoki, Saito, Park, et al., 2020).

\section{Study design}

Studies on the role of social situation followed a 2 (food: insect, typical) $\times 5$ (social situation: alone, friend, family, acquaintance, partner) within-participants experimental design. Studies on the role of locations assessed 2 (food: insect, typical) $\times 4$ (location: cafes, bars, pubs, food festivals) dimensions in which all of the factors were varied on a withinparticipant basis. The main dependent variable was ratings of willingness to eat. 
At the beginning of each study, the participants were asked their age, gender, and whether or not they had eaten insect-based foods previously. They also answered a question concerning the influence of contexts (Study 1: social situation; Study 2: locations) on their willingness to eat both typical and insect-based foods ('How much would you like to eat insect-based foods [typical foods] in the following situations (social situation: alone/with friend/family/acquaintance/partner for Study 1) or (locations: cafes/bars/pubs/food festivals for Study 2)?'. Subsequently, the participants responded to questions about relations between contexts and expected emotions ('How much do you expect fun [excitement] when you eat insect-based foods [typical foods] in the following situations (social situation: alone/with friend/family/acquaintance/partner for Study 1) or (locations: cafes/bars/pubs/food festivals for Study 2)?'. All ratings were given as responses made according to Likert scales ranging from 1 (not at all) to 7 (very much).

Study 3 was designed to replicate the main findings of Studies 1 and 2 using the actual product names of insect-based foods (mealworm burger, cricket chocolate bar) and typical foods (beef hamburger, chocolate bar) rather than insect-based foods as a general category. In addition, diverse expected emotions were used in Study 3 including pleasant and arousing (fun, excitement) as well as pleasant and less arousing (romance, tranquility). Study 3 involved the factors of social situation (Study 1) as well as locations (Study 2) with a procedure similar to Studies 1 and 2.

Finally, only for Study 1, the participants responded to the following question about the emotions that would likely lead them to eat typical and insect-based foods: 'How much would you like to eat insect-based foods [typical food] when you are in situations associated with the following feelings (fun/excitement/romance/tranquility)?' For all studies, the order of food types (insect/typical), social situation (alone/with friend/family/acquaintance/partner), locations (cafes/bars/pubs/food festivals), and expected emotions (fun/excitement/romance/tranquility) were randomized across participants. The details of questions and original questions (in Japanese) are shown in Supplementary material (Appendix).

\section{Statistical Analysis}

Repeated measures analysis of variance (ANOVA) was conducted to assess how social situation and locations are associated with people's expected willingness to eat insect-based 
foods and expected emotions. The dependent variables were ratings of the expected willingness to eat and expected emotions. Whenever an interaction term was observed, posthoc analysis was conducted in order to elucidate the details. This analysis was conducted using Shaffer's modified sequentially-rejective Bonferroni procedure. All of the ANOVAs and subsequent multiple testing were carried out using anovakun, a function of the R software.

In order to try and elucidate the relations between expected willingness to eat and expected fun/exciting feelings when eating insect-based foods with friends and pubs/food festivals, we conducted multiple regression analyses. Willingness to eat insect-based foods was used as a predictor, fun and exciting feelings when eating insect-based foods as explanatory variables, and variables related to eating typical foods (willingness to eat typical foods with friends, willingness to eat typical foods in pubs/food festivals), with the other emotional variables related to eating insect-based foods (romance, tranquility) used for no-interest explanatory variables. All of the statistical analyses were conducted using $\mathrm{R}$ software.

\section{RESULTS}

We grouped the results by themes. Firstly, we report the results of "Associations between expected emotions and willingness to eat insect-based foods (Study 1)". Then, we report the results: "On the role of social situation (Studies 1 and 3a)" and "On the role of locations (Studies 2 and 3b)".

\section{Associations between expected emotions and willingness to eat insect-based foods (Study 1)}

ANOVAs were conducted in order to assess the relations between expected emotions and people's expected willingness to eat insect-based foods. They followed the 2 (food: insect, typical $) \times 4$ (emotions: fun, excitement, romance, tranquility) within-participants study design. The analysis revealed main effects of the food types and emotions (food type, $F_{1,95}$ $=175.13, p<.001, \eta G 2=.329$; emotion, $\left.F_{3,285}=94.19, p<.001, \eta G 2=.168\right)$ as well as the interactions $\left(F_{3,288}=35.31, p<.001, \eta G 2=.580\right)$. In particular, the participants reported that they would be more willing to eat insect-based foods when they imagined being in those situations that they associated with fun and excitement rather than with romance and tranquility. In terms of typical foods, they predicted that they would be more willing to eat when experiencing fun and tranquil feelings than when experiencing exciting 
and romantic feelings instead. The results are summarised in Figure 1. The results of all pairwise comparisons are shown in Supplementary material (Table S1).

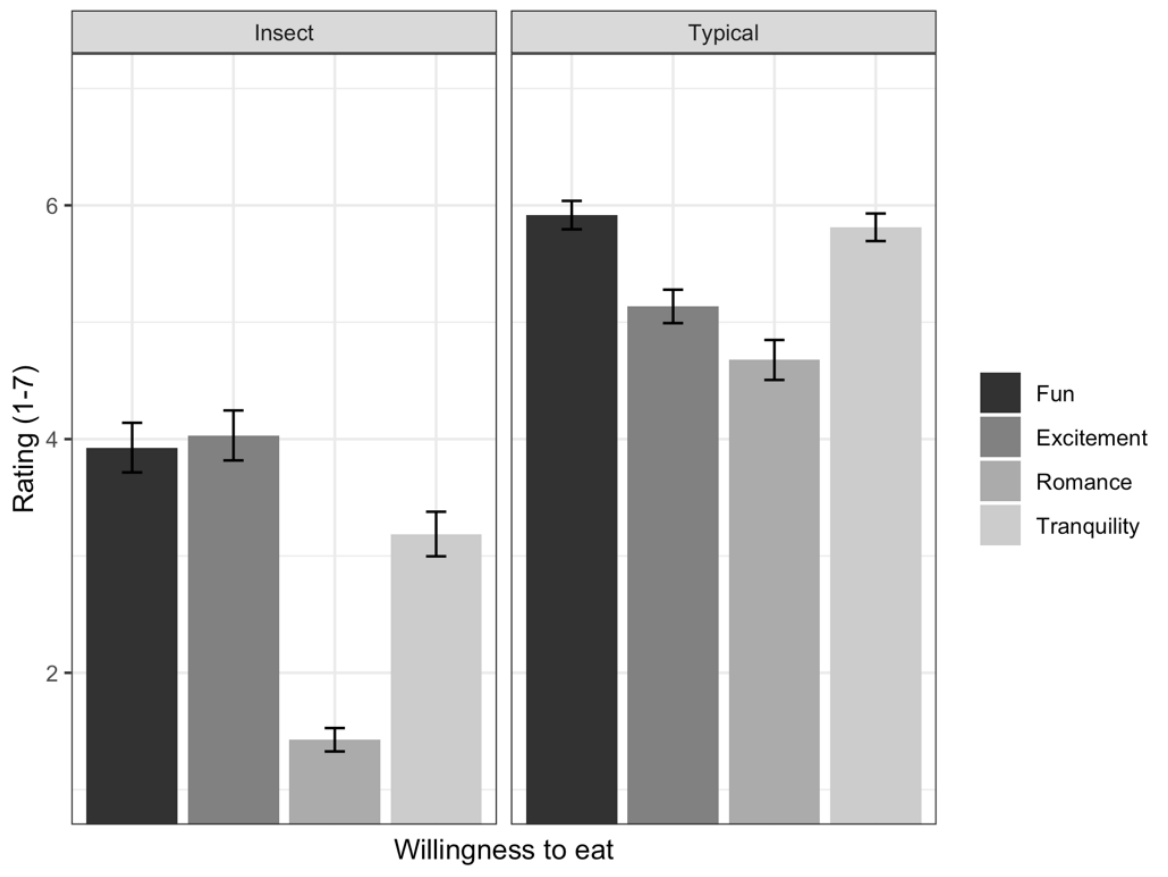

Figure 1. Results of Study 1. Graphs highlight the relations between expected emotions and expected willingness to eat. Ratings on a 1-7 scale ('not at all' to 'very much'). Error bars represent the standard errors of the mean.

\section{On the role of social situation (Studies 1 and 3a)}

A visual summary results are also is presented in Figures 2 and 3. Statistical summaries of ANOVAs and all pairwise comparisons are presented in Supplementary material (Tables S2$3)$.

\section{Relationship between social situation and willingness to eat}

The analyses of Studies 1 and 3a both revealed significant main effects of the type of food and location as well as the interactions between factors. The participants expected that they would be more willing to eat insect-based foods with friends than in the other social situation.

Relationship between social situation and positive arousing emotions (fun and excitement) 
The analyses of Studies 1 and 3a both revealed significant main effects of the type of food and location as well as interactions between these factors. Eating insect-based foods with friends was rated as more fun and exciting than in the other social situation.

The relations between social situation and positive calming emotions (romantic and tranquil)

The analysis of Study 3a revealed significant main effects of both the type of food and location as well as the interaction between these factors. Perhaps unsurprisingly, for both insect-based and typical foods, eating alone was rated as more tranquil than any of the other social situation. Additionally, eating insect-based foods with an acquaintance was rated as more tranquil than with a partner. In terms of romantic feelings, no significant differences were found for insect-based foods amongst the various social situation. 


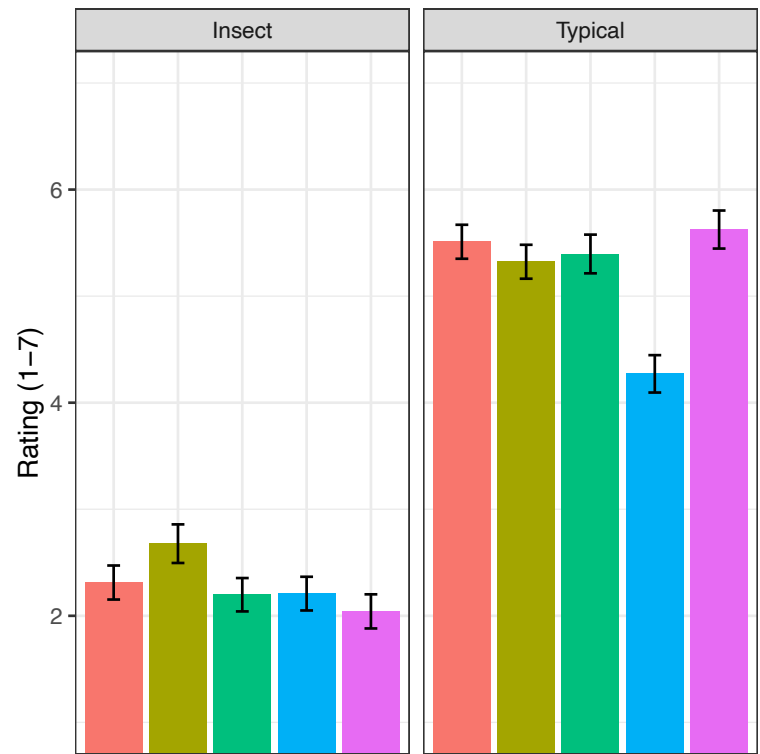

Willingness to eat

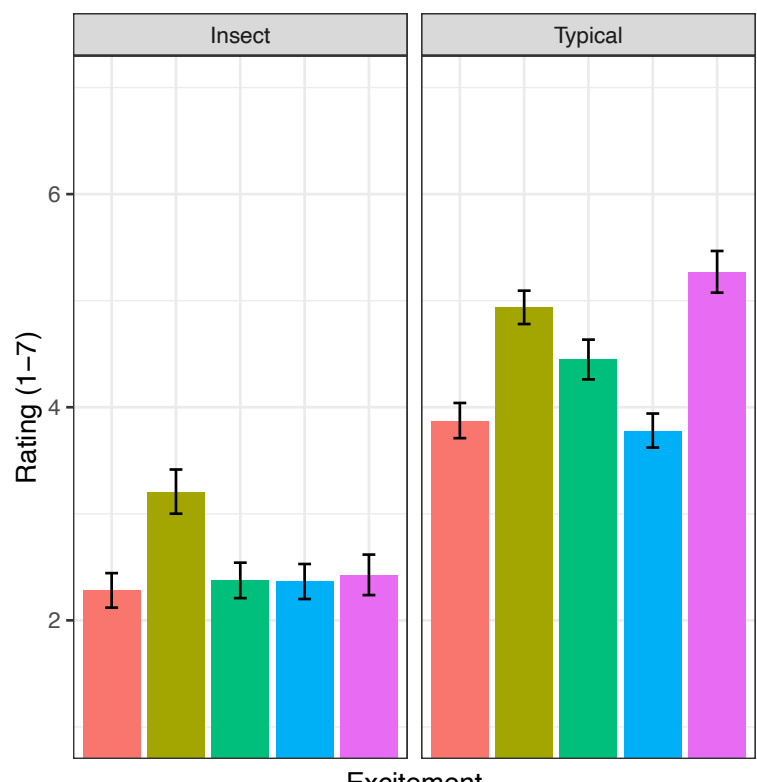

Excitement

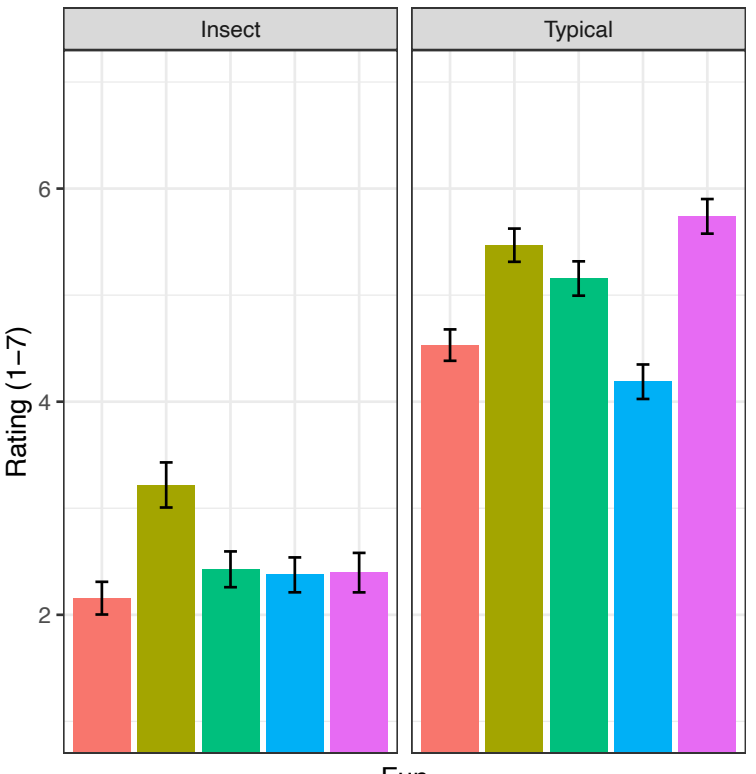

Fun

Figure 2. Results of Study 1. Graphs highlight the relationships between social situation and expected willingness to eat/expected emotions. Ratings on a 1-7 scale ('not at all' to 'very much'). Error bars represent the standard errors of the mean. 


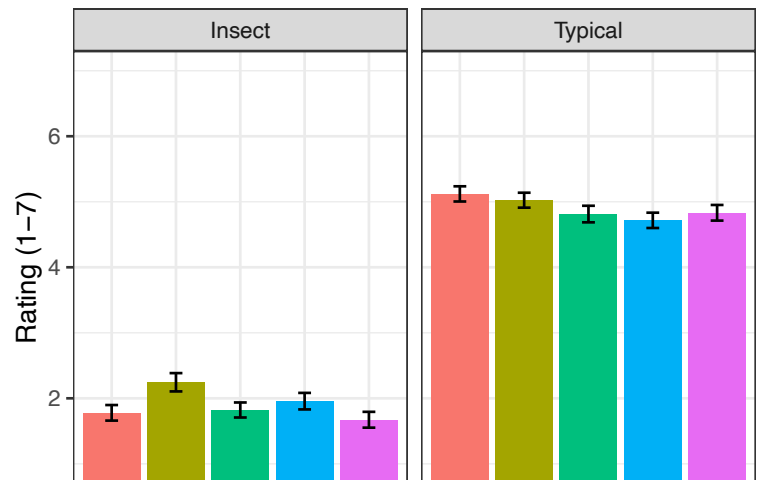

Willingness to eat

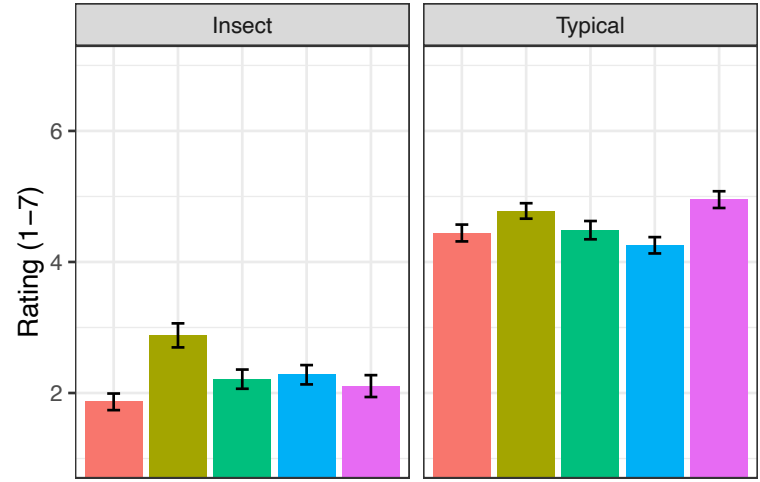

Excitement

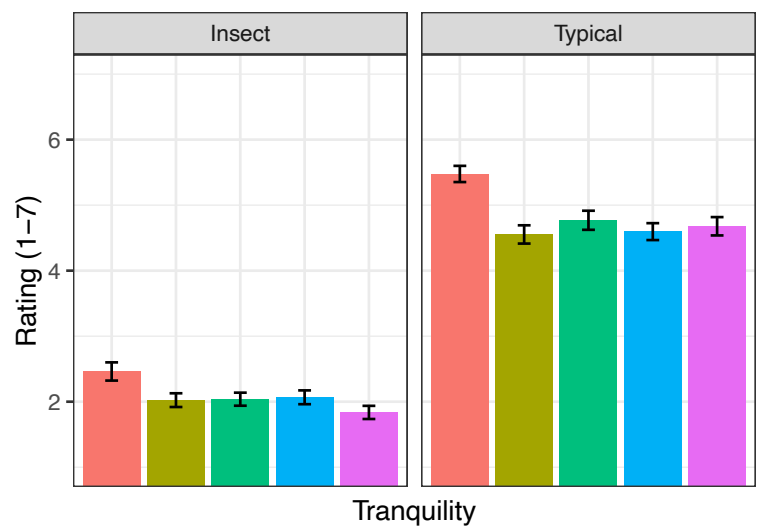

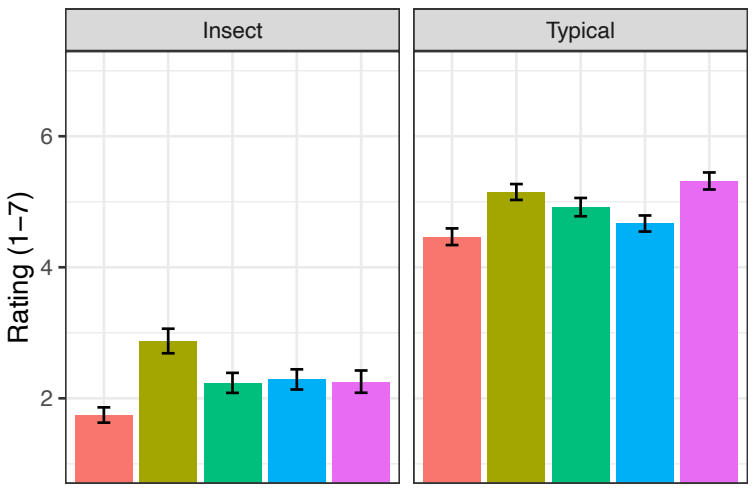

Fun

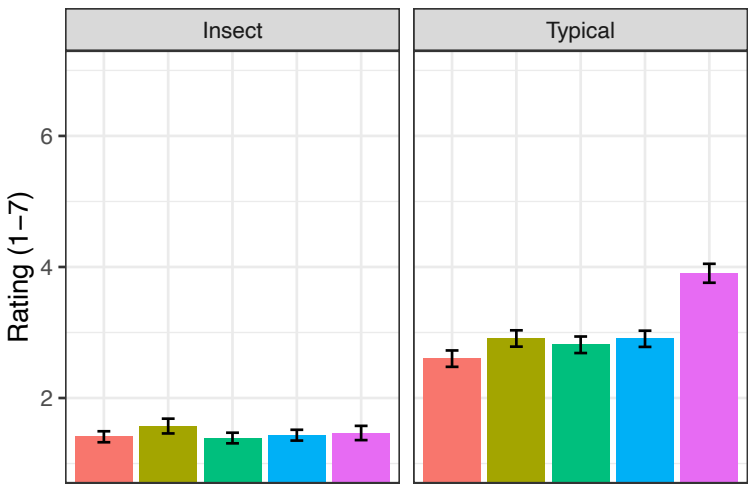

Romance

Alone

Friend

Family

Acquaintance

Partner

Figure 3. Results of Study 3a. Graphs highlight the relations between social situation and expected willingness to eat/expected emotions. Ratings on a 1-7 scale ('not at all' to 'very much'). Error bars represent the standard errors of the mean. 


\section{Multiple regression analysis}

The results of Study 1 revealed that expected feelings of fun and excitement (fun: $\beta=0.381$, $S E=0.145, t=2.634, p=.010$; excitement: $\beta=0.466, S E=0.147, t=3.177, p=.002$ ) when eating with friends contributed significantly to the participants' expected willingness to eat insect-based foods. The results of Study 3 a revealed that expected feelings of fun $(\beta=0.324$, $S E=0.111, t=2.922, p=.004)$, but not excitement $(\beta=0.211, S E=0.116, t=1.822, p$ $=.072$ ), associated with eating insect-based foods with friends were found to contribute significantly to expected willingness to eat insect-based foods. Taken together, the results suggest that fun feelings from eating insect-based foods with friends provide a unique explanation for insect-based food acceptance beyond other factors (e.g., willingness to eat typical foods with friends).

\section{On the role of locations (Studies 2 and $3 b$ )}

\section{RESULTS}

A visual summary of the results is presented in Figures 4 and 5. Statistical summaries of ANOVAs and all pairwise comparisons are presented in Supplementary material (Tables S2 and S4). 

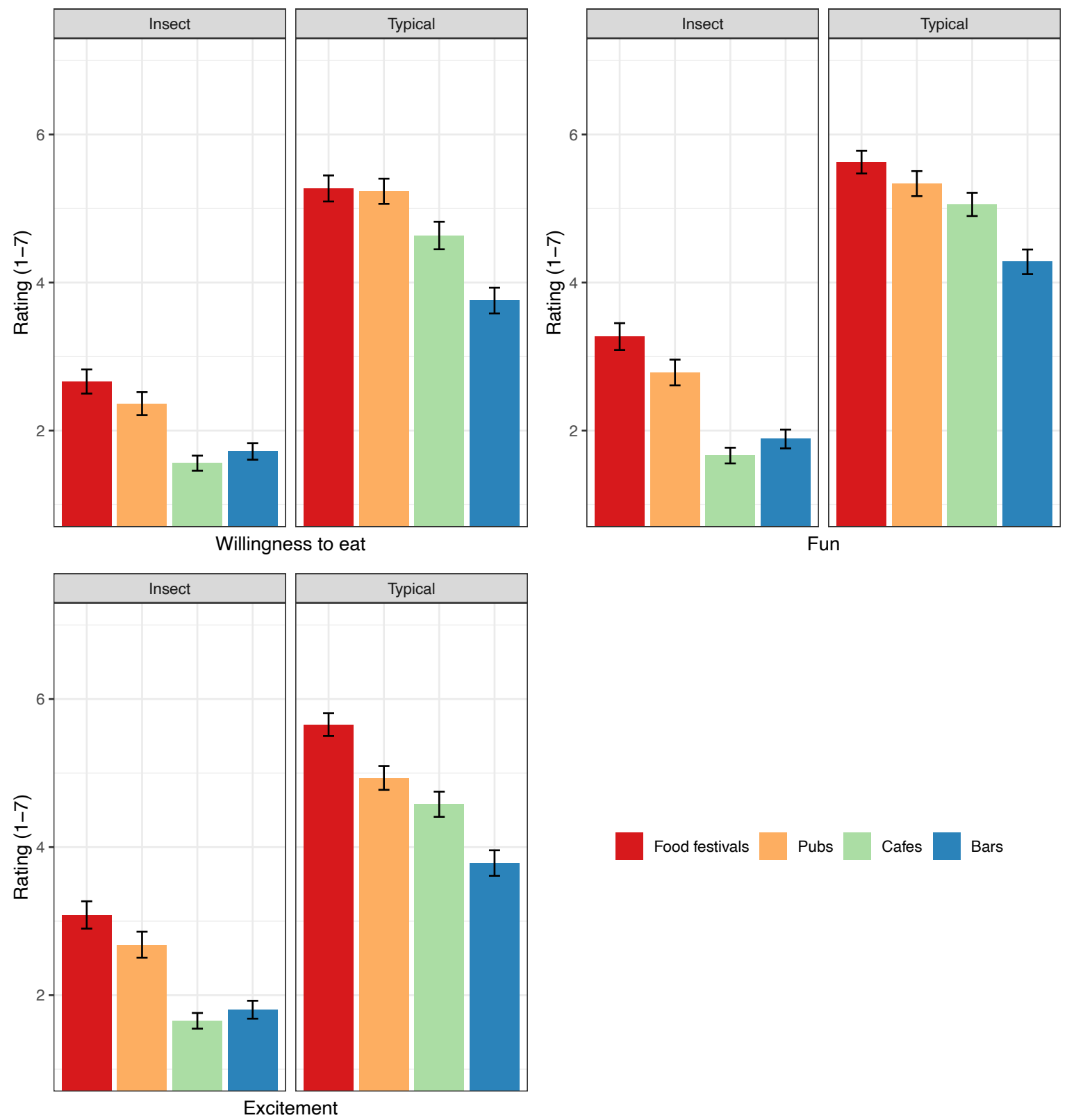

Food festivals Pubs Cafes Bars

Figure 4. Results of Study 2. Graphs highlight the relations between locations and expected willingness to eat/expected emotions. Ratings are given on a 1-7 scale ('not at all' to 'very much'). Error bars represent the standard errors of the mean. 

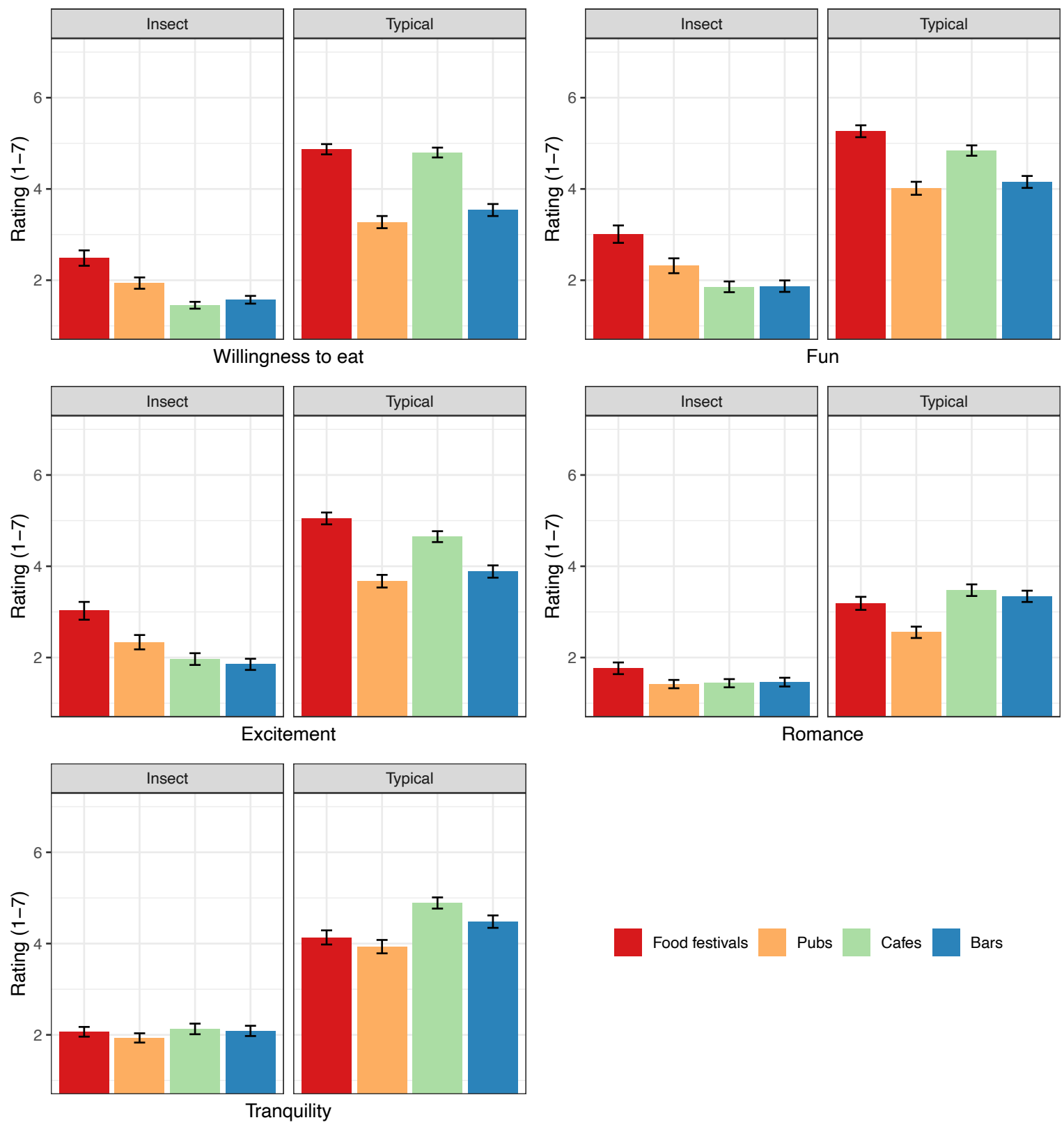

Food festivals Pubs Cafes Bars

Figure 5. Results of Study 3b. Graphs highlight the relationships between locations and expected willingness to eat/expected emotions. Ratings on a 1-7 scale ('not at all' to 'very much'). Error bars represent the standard error.

\section{Relationship between location and willingness to eat}

The analyses of Studies 2 and $3 b$ both revealed significant main effects of the type of food and location as well as an interaction between these factors. The results of Study 2 revealed that for both insect-based and typical foods, participants expected that they would be more willing to eat insect-based foods at food festivals and pubs than at cafes and bars. They also reported that they would also be more willing to eat insect-based and typical foods at food festivals than at pubs. However, for insect-based foods, the ratings of expected willingness to eat did not differ between cafes and bars. For typical foods, people expected that they would be more willing to eat them there than in bars. 
The results of Study $3 \mathrm{~b}$ revealed that for both insect-based foods, the participants expected that they would be more willing to eat at food festivals than at bars and pubs, respectively. Although they expected that they would be more willing to eat insect-based foods at food festivals than at cafes, the rating of expected willingness to eat did not differ between food festivals and cafes for typical foods. Although eating insect-based foods at pubs was preferred over eating them at cafes, the opposite expectation held for typical foods.

\section{Relationship between location and positive arousing emotions (fun and excitement)}

The analyses of Studies 2 and $3 \mathrm{~b}$ both revealed main effects of the type of food and location as well as an interaction between these factors. For both insect-based and typical foods, food festivals and pubs were rated as more fun and exciting than cafes or bars.

\section{Relationship between location and positive calming emotions (romantic and tranquil)}

Analysis of the results of Study $3 b$ revealed main effects of both the type of food and location as well as a significant interaction between these factors. For insect-based foods, food festivals were rated as more romantic than the other locations. In contrast, cafes were rated as more romantic than food festivals for typical foods. Eating typical foods in cafes and bars was rated as likely to be more tranquil than food festivals or pubs. In the case of insectbased foods, no significant difference was found in the expected feelings of tranquility across locations.

\section{Multiple regression analyses}

The results of Study 2 revealed that, when eating in pubs, expected feelings of fun $(\beta=$ $0.724, S E=0.147, t=4.934, p<.001)$, but not excitement $(\beta=0.035, S E=0.149, t=0.236$, $p=.814)$, contributed to expected willingness to eat insect-based foods. When eating at food festivals, both expected feelings of fun and excitement (fun: $\beta=0.490, S E=0.141, t=3.484$, $p<.001$; excitement: $\beta=0.312, S E=0.135, t=2.306, p=.023$ ) contributed to expected willingness to eat insect-based foods.

The results of Study $3 \mathrm{~b}$ revealed that, when eating at a pub, both expected feelings of fun and excitement (fun: $\beta=0.398, S E=0.119, t=3.332, p=.001$; excitement: $\beta=0.348, S E=$ $0.126, t=2.760, p=.007)$ contribute to expected willingness to eat insect-based foods. When 
eating at food festivals, expected feelings of excitement $(\beta=0.444, S E=0.121, t=3.669, p$ $<.001)$, but not fun $(\beta=0.242, S E=0.125, t=1.937, p=.056)$, contribute to the expected willingness to eat insect-based foods. These results suggest that positive arousing emotions from pubs and food festivals provide unique explanations for insect-based food acceptance beyond the other factors (e.g., willingness to eat typical foods at food festivals/pubs), although the findings were somewhat complex.

\section{Discussion}

The results of Study 1 demonstrate that people expected that they would be more willing to eat insect-based foods with friends (vs. alone, family, acquaintance, partner). Meanwhile, the results of Study 2 revealed that people expected that they would be more willing to eat insectbased foods at food festivals and pubs (vs. cafes and bars). The results of Study 3 replicated the main findings of Studies 1 and 2, using actual insect-based foods names (mealworm burger, cricket chocolate bar). Moreover, the contexts where people would be more willing to eat insect-based foods are associated with positive arousing emotions (fun and exciting feelings). Taken together, therefore, these findings reveal contextual determinants of eating insects. They provide a number of practical implications on how/where to introduce such foods or create appropriate situations to increase the acceptance of eating insect-based foods.

\section{People eating together and emotions}

The results help to differentiate the roles of familiarity of people eating together on insectbased food acceptance. According to earlier research, the presence of familiar individuals increases food intake (Ruddock et al., 2019). For example, the results demonstrate that meals eaten with friends, family, or with one's spouse tend to be larger than those consumed with other companions (e.g., Ruddock et al., 2019; Spence, 2017). However, the results of Studies 2 and 3 demonstrated that familiar companions have differential roles in the acceptance of eating insect-based foods. In particular, our participants reported that they thought they would be more likely to try insect-based foods with friends than with other familiar companions (family, partner). It would seem that these results can partially be explained by the different emotions that are associated with the respective companions (e.g., friends and fun/excitement, partner and romance). If more people expect fun and exciting feelings when eating insect-based foods with friends, then more people will presumably be willing to try 
them. Taken together, therefore, these findings highlight that eating with familiar individuals has differential roles on insect-based food acceptance because of distinct emotions associated with the respective companions.

\section{Locations (or contexts) and emotions}

Previous research has shown that food acceptance and preferences differ in terms of where the food is served (Cardello \& Meiselman, 2018; Spence, 2017). However, the roles of the emotions that are associated with specific location on eating remains largely unstudied. An earlier study showed that appropriate locations when eating food elicit a range of positive emotions (e.g., excitement, joy, happiness; Piqueras-Fiszman \& Jaeger, 2015). These results therefore extend those of earlier studies of product-context propriety on emotion associations and show that fun and exciting feelings are associated with appropriate emotions for disliked foods such as insect-based foods.

\section{Limitations and future research}

One relevant limitation is that we use imaginary scenarios for environmental situations. Using an online platform, this study involved participants imagining that they were with companions or at particular eating establishments. As such, this condition might be expected to engender some practical difficulties. Preparing many situations (e.g., social situation with friends, and locations of food festivals) are not impossible but undoubtedly very demanding (e.g., expensive, time-consuming, and hard to control the nature of the social interaction). Although this type of manipulation has, on occasion, been used previously (PiquerasFiszman \& Jaeger, 2014), the outcomes may not reflect the actual roles of environments for insect-based food acceptance. A second limitation of the present study is the number and valence of emotions that were used. Based on the core affect theory (Prescott, 2017, Russell, 2003), we chose emotions largely covering positive forms of high-arousal (fun and exciting) and low-arousal (romantic and tranquil). However, there are also a number of positive arousing (e.g., joy, surprise) and negative emotions (e.g., sad, disgust) (Cowen \& Keltner, 2017) that were not included in the present study. Further studies will therefore be needed in order to investigate which specific emotions are most associated with insect-based food acceptance. A final limitation of the present study is the typical issue concerning within participants design. This study design likely involves demand effect. For example, 
participants might interpret the researchers' intention and change their behaviour accordingly. Further study should replicate the current findings using between-participants design.

\section{References}

Alemu, M. H., Olsen, S. B., Vedel, S. E., Pambo, K. O., \& Owino, V. O. (2017). Combining product attributes with recommendation and shopping location attributes to assess consumer preferences for insect-based food products. Food Quality and Preference, 55, 45-57.

Berger, S., Christandl, F., Bitterlin, D., \& Wyss, A. M. (2019). The social insectivore: Peer and expert influence affect consumer evaluations of insects as food. Appetite, 141, 104338.

Cardello, A. V., \& Meiselman, H. L. (2018). Contextual influences on consumer responses to food products. In G. Ares \& P. Varela, (Eds.), Methods in consumer research, Vol. 2. Alternative approaches and special applications (pp. 3-54). Sawston, Cambridge: Woodhead Publishing.

Cowen, A. S., \& Keltner, D. (2017). Self-report captures 27 distinct categories of emotion bridged by continuous gradients. Proceedings of the National Academy of Sciences of the USA, 114(38), E7900-E7909.

Deroy, O., Reade, B., \& Spence, C. (2015). The insectivore's dilemma. Food Quality \& Preference, $44,44-55$

Hartmann, C., \& Siegrist, M. (2017). Consumer perception and behaviour regarding sustainable protein consumption: A systematic review. Trends in Food Science \& Technology, 61, 11-25.

Higgs, S., \& Thomas, J. (2016). Social influences on eating. Current Opinion in Behavioral Sciences, $9,1-6$.

Lammers, P., Ullmann, L. M., \& Fiebelkorn, F. (2019). Acceptance of insects as food in Germany: Is it about sensation seeking, sustainability consciousness, or food disgust? Food Quality and Preference, $77,78-88$.

Motoki, K., Saito, T., Park, J., Velasco, C., Spence, C., \& Sugiura, M. (2020). Tasting names: Systematic investigations of taste-speech sounds associations. Food Quality and Preference, 80 , 103801.

Motoki, K., \& Sugiura, M. (2018). Disgust, sadness, and appraisal: Disgusted consumers dislike food more than sad ones. Frontiers in Psychology, 9:76. 
Piqueras-Fiszman, B., \& Jaeger, S. R. (2014). The impact of the means of context evocation on consumers' emotion associations towards eating occasions. Food Quality and Preference, 37, $61-70$.

Piqueras-Fiszman, B., \& Jaeger, S. R. (2015). The effect of product-context appropriateness on emotion associations in evoked eating occasions. Food Quality and Preference, 40, 49-60.

Prescott, J. (2017). Some considerations in the measurement of emotions in sensory and consumer research. Food Quality and Preference, 62, 360-368.

Ruddock, H. K., Brunstrom, J. M., Vartanian, L. R., \& Higgs, S. (2019). A systematic review and meta-analysis of the social facilitation of eating. The American Journal of Clinical Nutrition, $110(4), 842-861$.

Russell, J. A. (2003). Core affect and the psychological construction of emotion. Psychological Review, 110(1), 145-172.

Spence, C. (2017). Gastrophysics: The new science of eating. London, UK: Viking Penguin.

Stephenson, M. T., Hoyle, R. H., Palmgreen, P., \& Slater, M. D. (2003). Brief measures of sensation seeking for screening and large-scale surveys. Drug and Alcohol Dependence, 72(3), 279-286.

Verbeke, W. (2015). Profiling consumers who are ready to adopt insects as a meat substitute in a Western society. Food Quality and Preference, 39, 147-155.

Willett, W., Rockström, J., Loken, B., Springmann, M., Lang, T., Vermeulen, S., ... \& Jonell, M. (2019). Food in the anthropocene: The EAT-Lancet Commission on healthy diets from sustainable food systems. The Lancet, 393(10170), 447-492.

Zuckerman, M. (1990). The psychophysiology of sensation seeking. Journal of Personality, 58(1), $313-345$. 